\title{
The Identification of Speed Regulation Systems Parameters for Hydraulic Turbogenerators
}

\author{
Missael Fajardo*, Joseph Guzmán ${ }^{\dagger}$, Walter Vargas ${ }^{\ddagger}$, Jaime Cepeda ${ }^{\S}$, and Javier Urquizo \\ Escuela Superior Politécnica del Litoral, ESPOL, FIEC \\ Campus Gustavo Galindo Km 30.5 Vía Perimetral, Guayaquil, Ecuador \\ Email:*mwfajard@espol.edu.ec, ${ }^{\dagger}$ josanguz@espol.edu.ec, ${ }^{\boldsymbol{9}}$ jurquizo@espol.edu.ec \\ Operador Nacional de Electricidad - CENACE, Quito , Ecuador \\ Email: ${ }^{\ddagger}$ Wvargas@cenace.org.ec, ${ }^{\S}$ jcepeda@ $@$ cenace.org.ec
}

\begin{abstract}
In this paper, we begin research on primary frequency control in Ecuador, in the same way as has been done for many years for secondary control. We analyse primary frequency regulation, and the respective parameters of identification, made using the heuristic optimization method known as Particle Swarm Optimization. This is applied with the speed regulator of a hydraulic turbine-generator group, to recognize those parameters with a higher influence o $n t h$ e $p$ during disturbances or events that alter the system frequency. To observe the frequency response, load shedding tests were simulated on a test system with 39 buses, and a hydraulic turbogenerator was also analysed. The latter had a speed controller and is a typical simulator model of the HYGOV type. The results we obtained indicate that the identification, by the particle swarm algorithm, was able to tune a controller to approximate its response to the one desired, regardless of the number of tuned parameters. We preferred this method over other heuristic algorithms because it is easily understood, and has better computational efficiency $w$ i th $\mathbf{m}$ u ltiple simultaneous variables.
\end{abstract}

Keywords - Frequency response, Governors tuning, Heuristic method, Parameters identification, Particle swarm, Primary frequency control

\section{INTRODUCTION}

Power systems are unexpectedly exposed to many kinds of disturbances and faults, the causes of which can be sudden load or generation variations, or short circuits in transmission lines that interconnect to the system. This includes line disconnections which occur, giving rise to an energy imbalance between supply and demand connected to the transmission system, in turn causing an acceleration or deceleration of the machines, according to the disturbance. The energy balance consists of the fact that the generated power in an interconnected electric system always has to be approximated (or equal) to the consumed power by loads in the grid [1]. Therefore, the turbogenerator group has a speed controller which regulates the mechanical input power to the turbine, and the speed, with respect to the electrical power output variations of the generator; this controller is called a governor, and acts on the gate servomotors which allow the water entry to turbine blades.

The correct primary frequency regulation [2]-[4] aims to make the turbogenerators' response adequate according to the disturbance. One critical phase of primary control is to prevent

Digital Object Identifier (DOI):

http://dx.doi.org/10.18687/LACCEI2020.1.1.277

ISBN: 978-958-52071-4-1 ISSN: 2414-6390 the frequency from deviating to values outside acceptable operating ranges, and to stabilize them to a different value without collapsing the system. To succeed in this, generators should operate load shedding schemes and have adequate primary power reserves. The power system's capacity to endure a huge generation loss represents the reserve magnitude available in , online generators, and therefore it is a generation percentage that the machines do not deliver to the grid, such that they operate below their rated capacities.

The Ecuadorian electricity sector has been developing research on Automatic Generation Control (AGC) for some years, but this has been limited to secondary frequency regulation, where power interchange values between interconnected areas are involved, as in the case of Ecuador and Colombia case [5]. However, this paper will focus on a hitherto unexplored research question, for which at present there is no definitive answer, which in essence relate primarily to the development of primary control, and in this paper we propose a method of governor tuning by primary control using parameter identification.

The simulations in this paper involved a load shedding contingency, through which observed the response of the simulated governor, so that parameter identification could be executed to determine which unknown governor was being tuned.

During the frequency deviation and stabilization [1], four important factors intervene: generator inertia, governor droop, the load damping coefficient, and governor and turbine time constants. Inertia is the amount of kinetic energy stored in the rotors of the generators connected to the grid. The load damping coefficient [6] is a constant that relates the percentage change in power load consumed due to the percentage of frequency change. In this paper, the factors that we are going to analyse via parameter identification are the droop and time constants. These and others aspects of the primary regulation are discussed below.

\section{POWER SYSTEMS FREQUENCY RESPONSE}

The North American Electric Reliability Corporation (NERC) researchers [4] define frequency response as the mathematical expression of net power change due to a change in the frequency of interconnected areas; this is known as $\beta$

$1^{\text {th }}$ LACCEI International Multi-Conference for Engineering, Education, and Technology: "Engineering, Integration, and Alliances for a Sustainable Development" "Hemispheric Cooperation for Competitiveness and Prosperity on a Knowledge-Based Economy", July 27-31, 2020, Virtual Edition. 
(Beta) and is expressed in $\mathrm{MW} / \mathrm{Hz}$, but it is also commonly expressed in $\mathrm{MW} / 0.1 \mathrm{~Hz}$. This represents the power change in MW that caused a $1 \mathrm{dHz}$ change. The resulting frequency deviation is maintained until the primary regulation is replaced by the AGC action, which corresponds to secondary control. A typical response from the primary control is shown in Fig. $1[4]$.

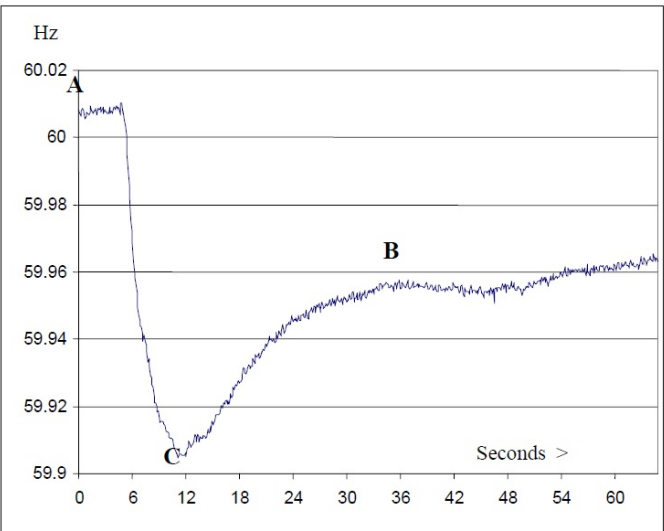

Fig. 1: Typical frequency response from the primary control

In Figure 1, three important points about the frequency response can be observed: point $\mathbf{A}$ is the pre-fault frequency value where the system was operating; point $\mathbf{C}$ is the minimum value and it reached a maximum of 12 or 16 seconds; stabilization is at point $\mathbf{B}$ because of the governor actuation, with a duration of between 20 and 60 seconds (or more). Thus, the frequency response is the change between points $\mathbf{A}$ and $\mathbf{B}$ due to the programmed droop [2]-[4]; its mathematical expression is seen in Equation 1.

$$
\Delta P_{i}=\beta * \Delta f
$$

If, after a perturbation, frequency $\mathbf{C}$ is higher than that programmed for the actuation of the first step of the load shedding scheme, then the governor and power reserves performance are adequate for the primary regulation [2], [3].

The droop factor is the proportion of the per unit frequency change and the active power output change, expressed as a percentage [2], [3], called $R$, in units of Hz/MW. Equation 2 represents the droop.

$$
R(\%)=\frac{\Delta f_{p . u .}}{\Delta P_{p . u .}} * 100
$$

Droop is a programmable parameter in the turbine governor. The value of the steady state frequency after a perturbation depends on the programmed droop, typically between $4 \%$ and $7 \%$, but $5 \%$ is the most common value for hydraulic generators. This means that if the frequency deviates by $5 \%$, there will be a $100 \%$ change in the power generated by the generator, to counter the frequency deviation; this is responsible for allowing the frequency deviation.

In the Ecuadorian electricity sector, with respect to primary control, the National Council of Electricity (CONELEC, its acronym in Spanish) is now the Agency of Regulation and Electricity Control (ARCONEL, its acronym in Spanish). It manages the electric sector in the country. Regulations establish [7] that the National Centre for Energy Control (CENACE, for its acronym in Spanish) is the entity which seasonally defines the optimum percentage of the required spinning power reserve for primary frequency regulation. Arias affirms [7] that in normal system operating conditions, the value of the primary reserves must cover random load variations. These are: 19.36 MW for minimum demand, 23.29 MW for medium demand, and 25.16 MW for maximum demand. Based on these values, the spinning reserve for primary regulation in Ecuador must be: $45 \mathrm{MW}, 52.5 \mathrm{MW}$ and $60 \mathrm{MW}$, respectively, for each value of random load variation.

\section{THE PARTICLE SWARM OPTIMIZATION (PSO) ALGORITHM}

PSO is a stochastic computational algorithm [8], [9]inspired by the natural behaviour of animal species and social psychology. It employs a population of candidate solutions that moves toward the optimum solution for an objective function. This population is constituted by the called particles that move across the space of the problem at a certain speed, while they register their better previous position. In a swarm [10], each individual (particle) follows the leader, which leads them to favourable zones to comply with some work. This behaviour is imitated by the algorithm to solve optimization problems.

PSO has the following principal elements:

- Particle: the candidate solution represented by a vector of $\mathrm{m}$ dimension, which is the number of optimized parameters in each particle, in $t$ number of iterations; the $j$ particle is represented as $X_{j}(t)=$ $\left[x_{j, 1}(t), x_{j, 2}(t), \ldots, x_{j, m}(t)\right]$;

- Population $P(t)$ : the set of $\mathrm{n}$ particles that form the swarm in the $t$ iteration, so that $P(t)=$ $\left[X_{1}(t), X_{2}(t), \ldots, X_{n}(t)\right]^{T}, j=1,2, \ldots, n$;

- Speed $V(t)$ : the speed at which particles move across the space. The particle speed is: $V_{j}(t)=$ $\left[v_{j, 1}(t), v_{j, 2}(t), \ldots, v_{j, m}(t)\right]$;

- Inertia weight $w(t)$ : a control parameter used in the speed impact previous to the current, which influences the compensation between global and local explorations of the particles;

- Swarm leader: the particle with the best aptitude value;

- Best global $X * *(t)$ : the best position of all the positions of the best individual, until the current iteration (swarm leader).

In Figure 2 [11], we show a reduced scheme of steps by which to execute the algorithm.

During each iteration, the aim is to actualize the particles positions and speed, the weight, and the leader.

\section{A. Parameters Identification}

The parameter identification of the governor [11] which we can observe as a black box aimed to determine the gains, time constants and other parameters that constrain the governor, so that we can establish a robust control system in a wide range of operating states. In this paper, we exclusively employ the PSO algorithm to do this. The identification tunes the governor 


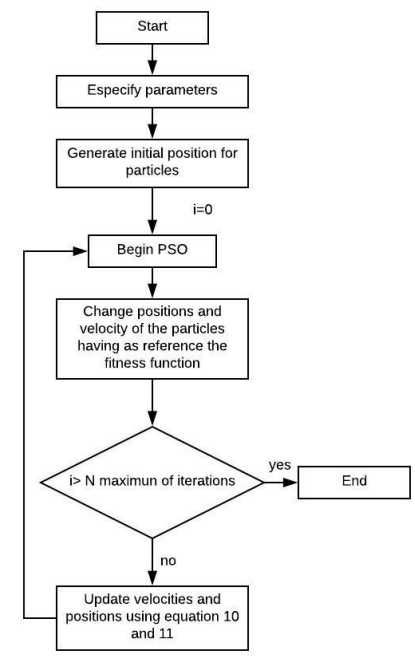

Fig. 2: Steps in the PSO algorithm

to obtain the desired responses, and this has been employed in Ecuador for secondary control. However, now we propose to begin governor tuning with primary control.

The objective function of parameter identification is to minimize error or difference, in an iterative way, between the signals obtained in the field and the governor's signal simulated in this paper. For this, we employ a governor model called a HYGOV [12], which is a standard, simple mechanical governor. It is this governor that we use in the simulated model, and Fig. 3 [13] shows its scheme.

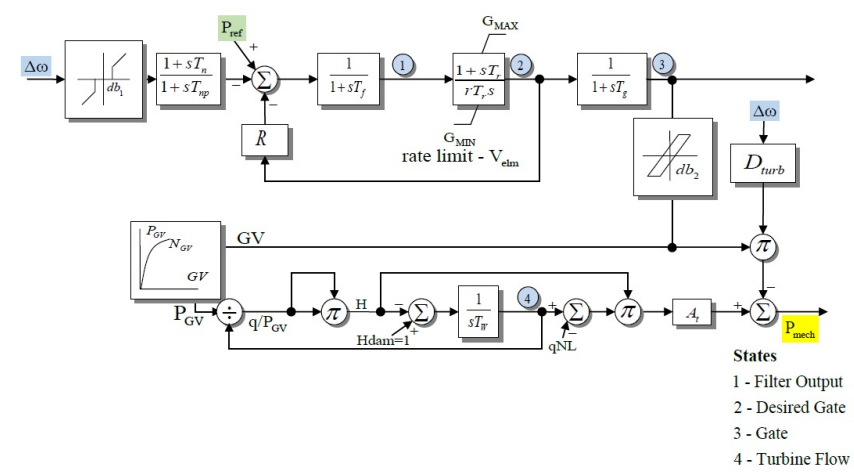

Fig. 3: Block scheme of the HYGOV governor model

The scheme shows two reference signals and two important output signals. These are: the speed change reference and the electric power, as input signals; and the output gate signal (identified with the number 3 ) and the output of the turbine's mechanical power.

\section{B. Gaussian white noise}

Noise is define [14] as all sets of data, signal or general information that are irrelevant to the measure, or which distort and contaminate the principal signal. In measuring electric systems, where sensors or transducers are used, noise can exist before or after the measuring element. Gaussian white noise in electric circuits is called the Gaussian normal distribution of the voltage noise, in $V^{2} / \mathrm{Hz}$, which indicates the spectral power density of the distribution or the noise content per frequency unit. These are random voltage excursions.

\section{METHODOLOGY FOR PARAMETERS IDENTIFICATION}

The methodology followed in this paper (see Fig. 4) consists of the simulation of a load disconnection event in a 39-bus power system, as in Fig. 5, called a 39-bus New England by the Institute of Electrical and Electronic Engineers (IEEE) [15], followed by the simulation of parameter identification in the computational simulator DIgSILENT, PowerFactory.

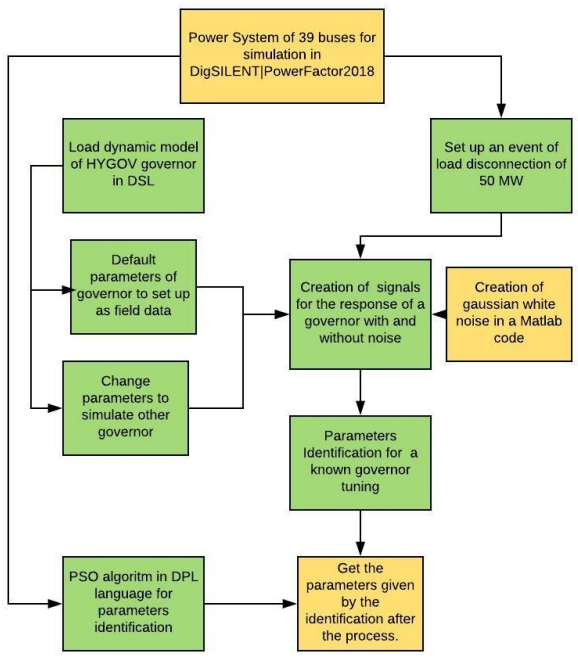

Fig. 4: Flowchart of the Methodology

We created a fictional field database for two reasons: first, parameter identification needs two signals, one from the field governor and the other from a simulated governor resulting from parameter identification; second, we had no real field data.

For this, we loaded the HYGOV governor into the Composite Model of the only hydraulic generator of the 39-bus system (generator G10) in PowerFactory, on the DIgSILENT Simulation Language (DSL) of the simulator. This contains dynamic models that are the generator controllers. Also, we loaded the load disconnecting event, which disconnected $50 \mathrm{MW}$ of bus 26 at five seconds of simulation; the total simulation lasted 120 seconds. This bus consists of a 139 MW load divided into two parts, so $89 \mathrm{MW}$ remain connected. Once this was done, we observed the turbine's mechanical power response and the turbogenerator's speed response, versus time; thus, these are the fictional field data, and formed two databases from them, with and without white noise.

We randomly generated white noise in the field governor response in the simulation, so that the signal looked like real data acquisition from a measurer connected to the grid. Fig. 6 [16] shows an example of this for a $50 \mathrm{~Hz}$ grid. Bear in mind that the operational frequency in Ecuador is $60 \mathrm{~Hz}$ whereas in Europe is generally $50 \mathrm{~Hz}$. 


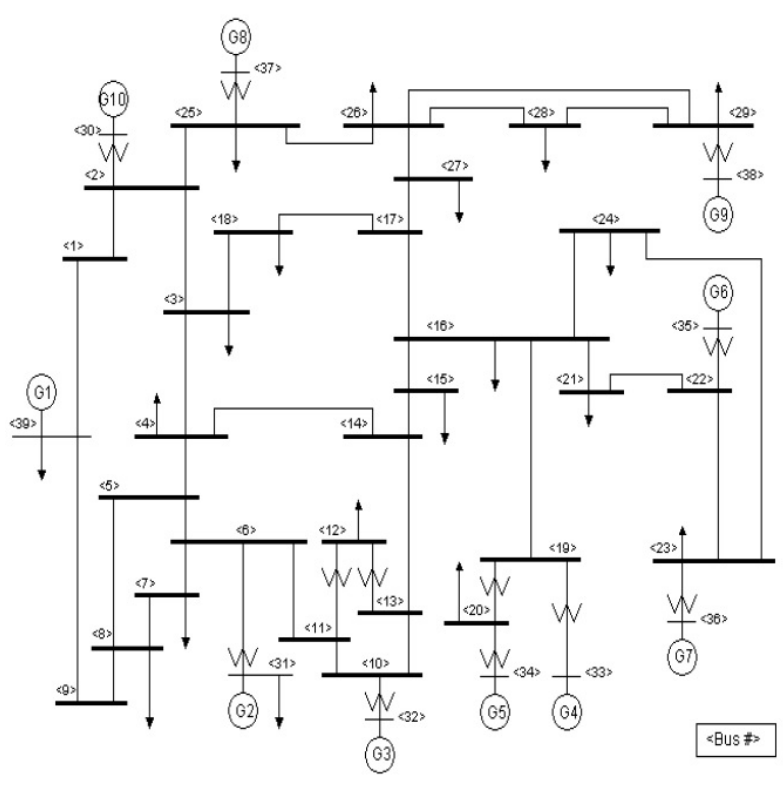

Fig. 5: 39-bus New England System

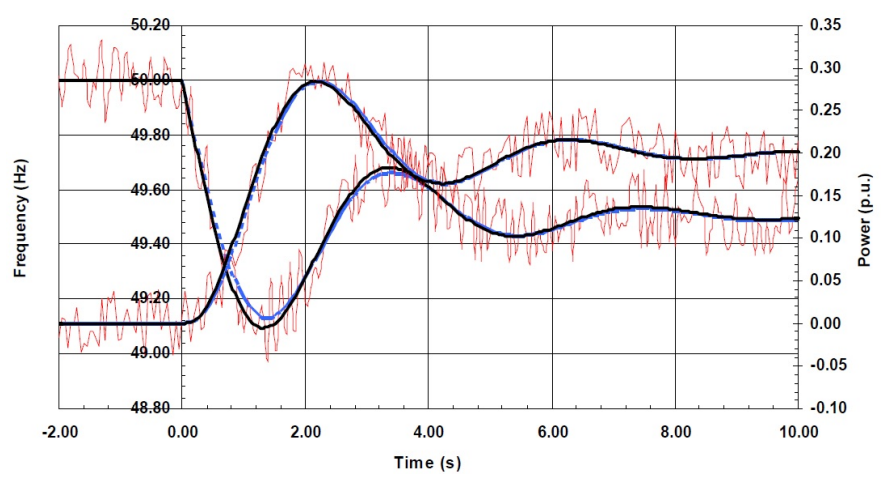

Fig. 6: Example of noise in a simulated signal

In Fig. 6, we observe (in red) the simulated noise signal, over the signal that is controller response (in blue). This allowed us to compare the parameter identification between signals with and without noise, and observe the effectiveness of the PSO method for signals with the characteristics from real data acquisition, and for noise free signals. Noise was added using MATLAB, and the database was exported from PowerFactory and imported into MATLAB to add noise, and then imported back to PowerFactory. The results for the speed response are shown in Fig. 7.

After we generated the database, we began the parameter identification with the governor which we will call the "known governor"; it was necessary to change its parameters so the response to disturbance was different to the field governor.

\section{A. Simulation parameters}

For the known governor, we decided to modify only one parameter in a controller with different actuation. In PowerFactory, the HYGOV governor has thirteen parameters, as we can see in Fig. 8.

The parameters observed in Fig. 8 correspond to predefined values in the HYGOV model, and so these are the values of
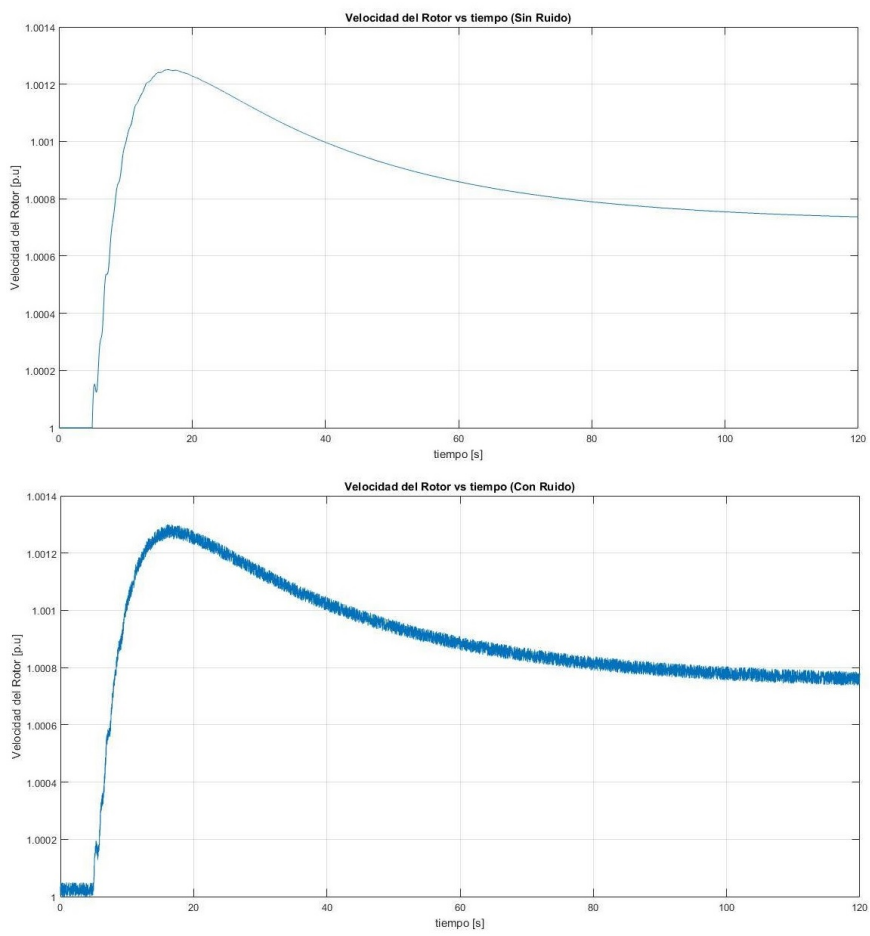

Fig. 7: Field HYGOV governor speed response. Top: data without noise. Bottom: data with noise

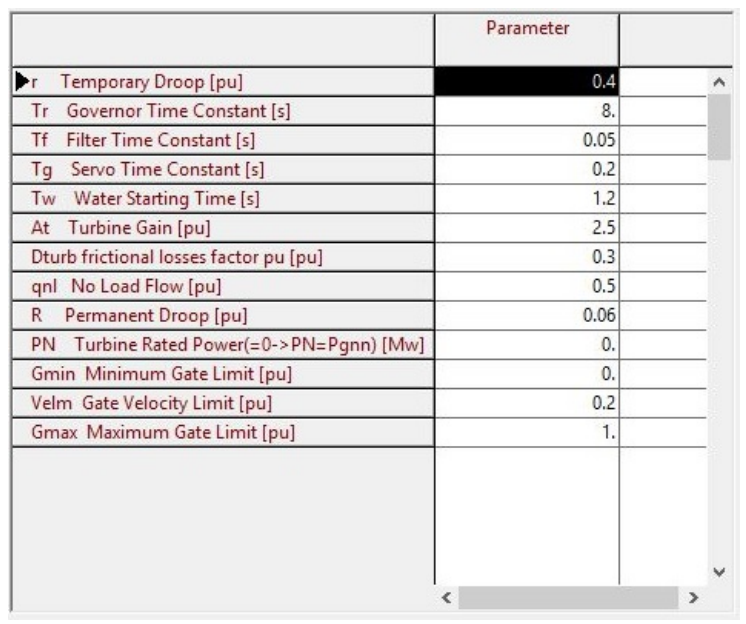

Fig. 8: Predefined parameters of HYGOV governor

the field governor. To obtain the known governor, we decided to change only the value of the parameter called Governor Time Constant Tr, which we changed from 8 to 3 seconds.

We facilitated the identification of ten parameters with the following: [13] temporary droop (r), governor time constant (Tr), filter time constant (Tf), servomotor time constant (Tg), water time constant (Tw), turbine gain (At), frictional losses factor in p.u. (Dturb), no-load water flow rate, which accounts for the fixed losses in the turbine (qnl), permanent droop (R), and gate speed limit (Velm). The identification of three parameters will be made with the following: the governor time constant (Tr), filter time constant (Tf), and servomotor time constant $(\mathrm{Tg})$. We do not consider the identification of 
the following parameters: PN, Gmin and Gmax, which are turbine rated power, and minimum and maximum gate limits, respectively.

\section{B. Objective function and PSO algorithm}

The objective function minimizes the quadratic error (difference to square) between the pairs of signals shown in Fig. 10, as in Equation 3.

$$
f\left(x_{1}, x_{2}\right)=\Sigma\left(x_{1 i}-x_{2 i}\right)^{2}
$$

where $f\left(x_{1}, x_{2}\right)$ is the objective function that the PSO algorithm has to minimize; $N$ is the number of iterations of the algorithm $x_{1}$ and $x_{2}$ are the signals from the field and known governors, respectively; $i$ is the current iteration. The minimization is not subject to restrictions.

In DSL language, in a Composite Model, we propose the entries of the objective function: sigread1, sigcal1, sigread2 and sigcal2, as is shown in Fig. 9.

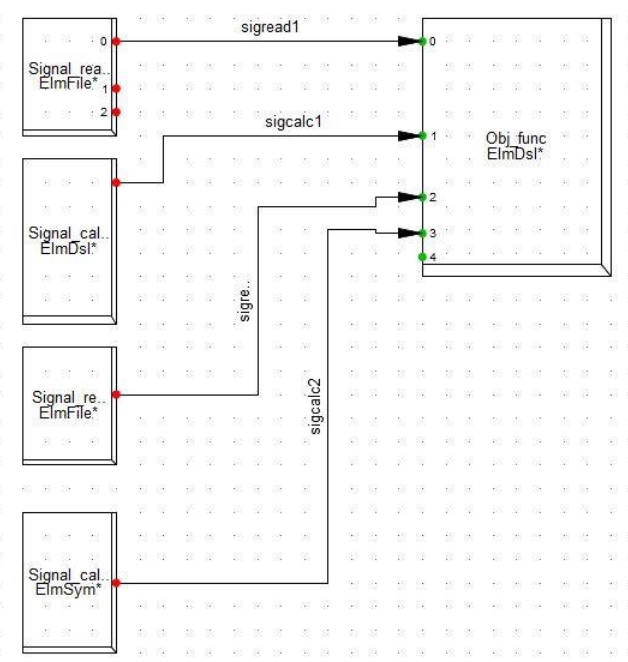

Fig. 9: Objective function of the Composite Model in DSL language

Once we created the events and established the objective function, the known HYGOV model was loaded. At this point, we began the PSO algorithm developed in a code in DIgSILENT Programming Language (DPL), to obtain the results of the tuning of the known governor by parameter identification for each one of the four tests.

\section{RESULTS OF THE PARAMETER IDENTIFICATION}

We made changes to obtain the known governor, which is different to the field governor, so that the governor responses were different; this can be observed in Fig. 10.

In Fig. 10, we observe (in green) the known governor responses (signals sigcal1 and sigcal2, for power and speed, respectively), and in red the field governor responses (signals sigread1 and sigread2, for power and speed, respectively). With these two signal pairs, we can identify the parameters which in tests will be used to identify three and ten parameters,

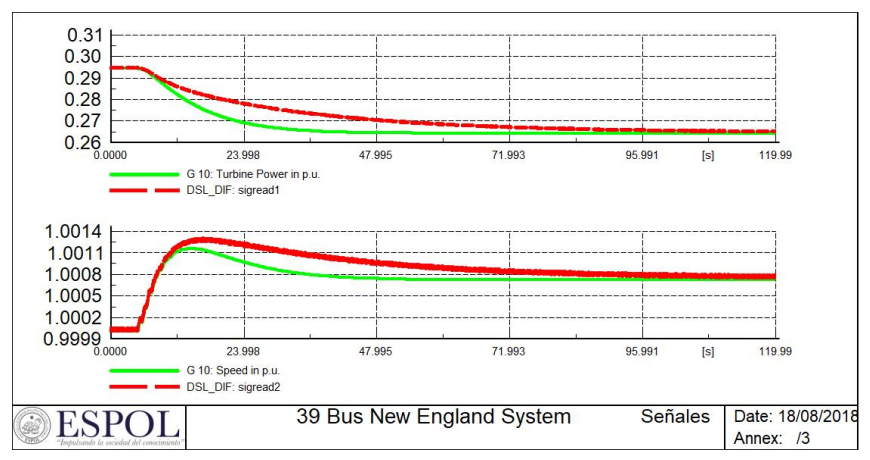

Fig. 10: Field and known governor responses, for signals with white noise

respectively. This was done with the aim of proving the efficiency of the PSO algorithm for the identification and verification of tuning the known governor, to obtain power and speed responses similar to the field governor. The tests we implemented were: identification of ten parameters with field data with and without noise, and identification of three parameters with field data with and without noise.

The results will be compared and shown in tables to aid the observation of their relationships. They will also be classified by test categories, that is tests of three and ten parameters, with and without white noise; the identifications of three and ten parameters were as described previously in the methodology section, and these will be tuned for the PSO algorithm for the execution of this method.

\section{A. Tuning results}

After we had executed the PSO algorithm for one identification, PowerFactory records the parameter values in the HGOYV governor, and we can observe this in a window shown in Fig. 8 (se figure Predefined parameters of HYGOV governor in Section IV.A). Thus, when we finalized one identification, the governor was tuned with the new values that the algorithm found, to represent the optimum of the planted objective function. With the HYGOV parameters, we built tables to compare the tuning values of each identification. From this, we show the tuning parameter results, according to the identification of either three or ten parameters, and comparing results with field signals with or without white noise.

1) Identification of three parameters: In Table I, we can observe the results for the field signal with and without white noise.

TABLE I: Tuning for the identification of three parameters

\begin{tabular}{|c|c|c|c|}
\hline Parameter & $\begin{array}{c}\text { Original } \\
\text { HYGOV }\end{array}$ & $\begin{array}{c}\text { Tuning } \\
\text { without } \\
\text { noise }\end{array}$ & $\begin{array}{c}\text { Tuning } \\
\text { with noise }\end{array}$ \\
\hline $\operatorname{Tr}[\mathrm{s}]$ & 8 & 8.022 & 8.405 \\
\hline $\operatorname{Tf}[\mathrm{s}]$ & 0.05 & 0.221 & 0.455 \\
\hline $\operatorname{Tg}[\mathrm{s}]$ & 0.2 & 0.062 & 0.069 \\
\hline
\end{tabular}


The results can be analysed to observe discrepancies between them, remembering that the aim of the algorithm, in both cases, was to obtain the same power and speed responses, resulting in parameter tuning that responds to the known governor in the same way as the field governor.

2) Identification of ten parameters: In Table II, we can observe the results for the field signal with and without white noise.

TABLE II: Tuning for the identification of ten parameters

\begin{tabular}{|c|c|c|c|}
\hline Parameter & $\begin{array}{c}\text { Original } \\
\text { HYGOV }\end{array}$ & $\begin{array}{c}\text { Tuning } \\
\text { without } \\
\text { noise }\end{array}$ & $\begin{array}{c}\text { Tuning } \\
\text { with noise }\end{array}$ \\
\hline $\mathrm{r}[\%]$ & 0.4 & 0.464 & 0.436 \\
\hline $\mathrm{Tr}[\mathrm{s}]$ & 8 & 8.228 & 9.069 \\
\hline $\mathrm{Tf}[\mathrm{s}]$ & 0.05 & 0.203 & 0.593 \\
\hline $\mathrm{Tg}[\mathrm{s}]$ & 0.2 & 0.243 & 0.01 \\
\hline $\mathrm{Tw}[\mathrm{s}]$ & 1.2 & 1.621 & 3.787 \\
\hline At [\%] & 2.5 & 2.989 & 2.999 \\
\hline Dturb [\%] & 0.3 & 0.299 & 0 \\
\hline Gnl [\%] & 0.5 & 0.137 & 0.065 \\
\hline $\mathrm{R}[\%]$ & 0.06 & 0.07 & 0.072 \\
\hline Velm [\%] & 0.2 & 0.105 & 0.121 \\
\hline
\end{tabular}

Even though these are the tuning results for ten parameters, and in both cases the algorithm should give the same power and speed responses, we can see important differences in parameter values. The fact that each identified parameter response should be the same will be observed below analysing the graphics.

\section{B. Speed and power responses}

The graphics of the turbine mechanical power response and turbogenerator group speed response are now given for tests with and without noise in field data. In Fig. 11, we can observe the results of parameter tuning for field data without noise. The red and green colours represent the field governor power and speed signals, respectively. The blue and brown dotted lines represent the known governor power and speed signals, respectively.

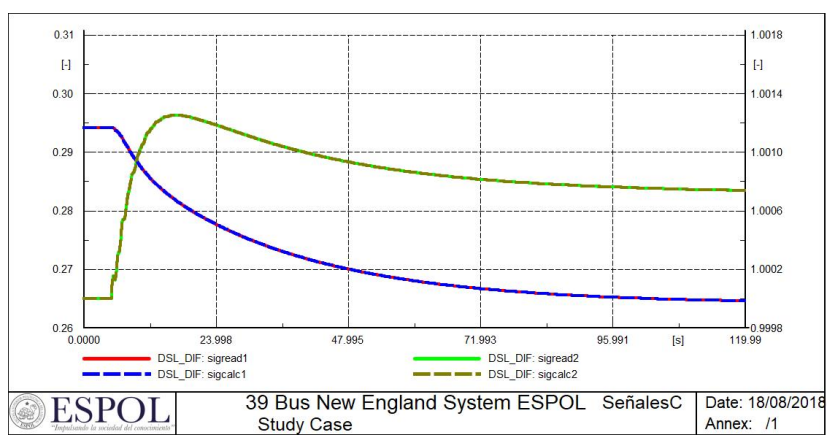

Fig. 11: HYGOV governor responses for identification with field data with noise

In Figure 12, we observe the parameter tuning responses for field data with noise.

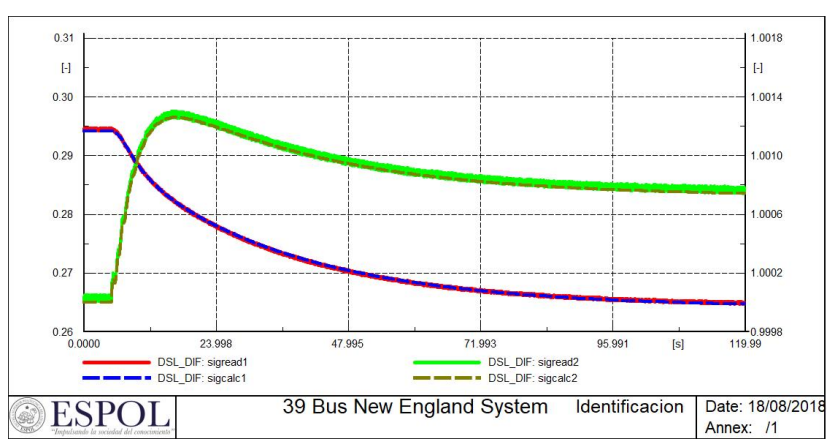

Fig. 12: HYGOV governor responses for identification with field data without noise

The colour distribution in the figures below is the same as for Fig. 12. The notable difference now is the distortion of the two field governor signals (sigread1 and sigread2); the known governor signals (sigcal1 and sigcal2) still had the same appearance as a simulation signal, that is, without noise.

In both cases, the figures for the identification of three and ten parameters gave the same pair of answers, that is, the sigcall signal was equal for both the three and ten parameter identifications, and the same occurred with the sigcal 2 signal. These results are reasonable because, for each case with and without noise, the PSO algorithm must approximate the power and speed responses to the field signal, which are unique regardless the number of identified parameters. The algorithm found a set of parameter values for the governor, and so it gave power and speed responses equal to the field governor, for the load disconnection event simulated as a test. This identification method peculiarity is an important conclusion to highlight in this paper, because it means that we must consider this algorithm's behaviour in future investigations.

\section{Objective function answers}

Now we will show the results of the PSO algorithm objective function across the parameter identification; in other words, the algorithm tried to converge to zero, after starting with high values, for the mean square error values in all cases. It is not possible to observe the changes in governor responses during iterations while the algorithm is being executed. However, in each iteration, we can observe different forms of responses, which, at the beginning of algorithm execution, did not look like the field data; in this way, we can see that the algorithm had "learned" from its own results, and decreased the quadratic error between the field objective signal and the known governor response.

1) Identification of three parameters: We can observe in Fig. 13 the objective function results without white noise for the field signal.

At the beginning of the identification, the algorithm gave an error near to 1000 . When the process continued, the error converged to zero, meaning that the algorithm approximated the known governor response to the field governor. We made one thousand iterations, which are shown on the horizontal axis of Figure 14, along with the objective function results with white noise for field signal. 


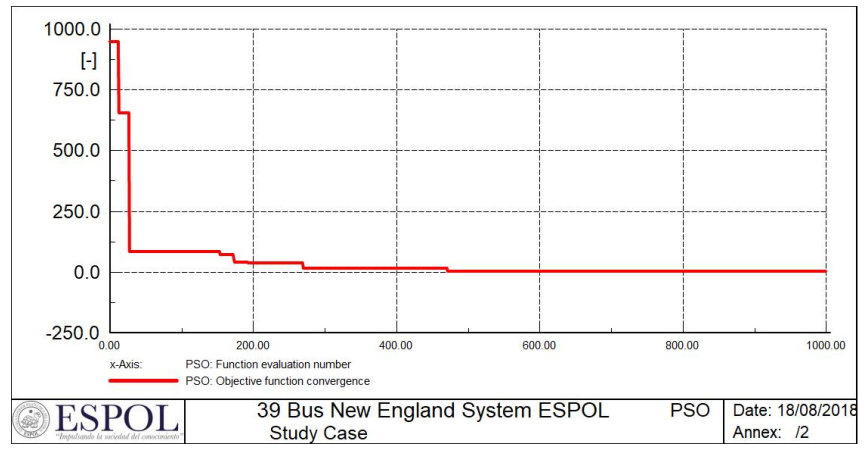

Fig. 13: Quadratic error for the identification of three parameters without white noise in field signal

Objective function results with white noise for field signal is illustrated in Fig. 14.

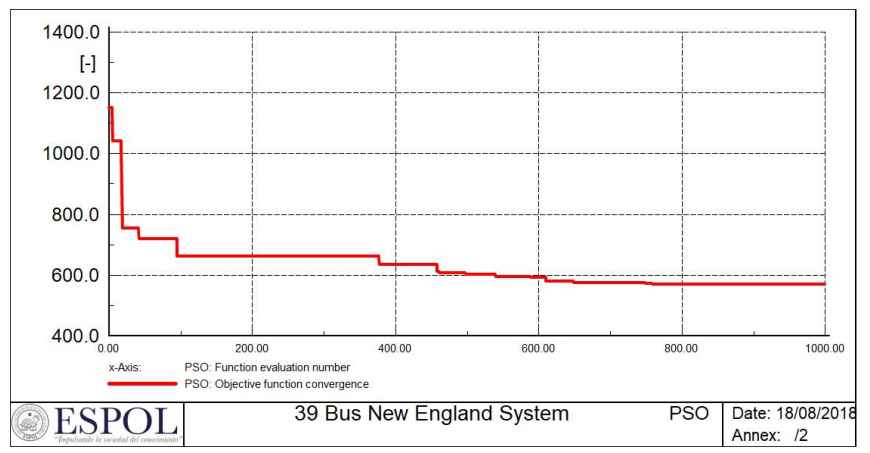

Fig. 14: Quadratic error for the identification of three parameters, with white noise in field signal

The result obtained in this test is completely different to the previous case: the quadratic error started with a value around 1150 , and converged to around 600 , also with one thousand iterations. Although it did not converge to zero in this case, we can see the mechanical power and speed graphics for the case of field signal with noise and ten parameters.

2) Identification of ten parameters: Objective function results without white noise for field signal are presented in Fig. 15.

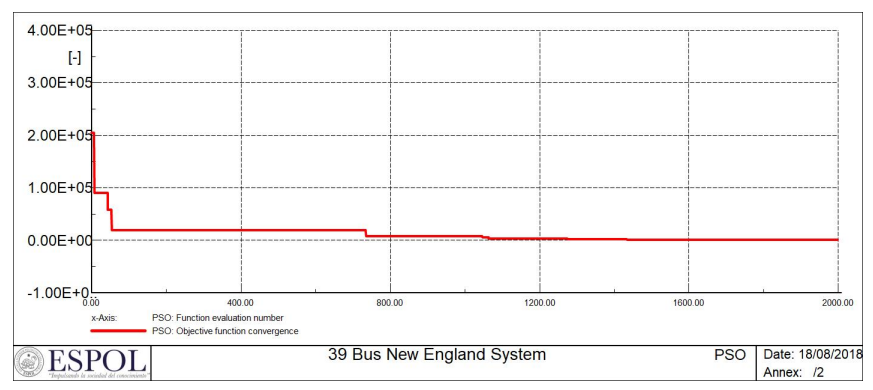

Fig. 15: Quadratic error for ten parameters identification, without white noise in field signal

This quadratic error started with a value around 200,000, but with the algorithm also converged to zero. We performed one thousand iterations for this case. The objective function results with white noise for the field signal can be seen in Fig. 16.

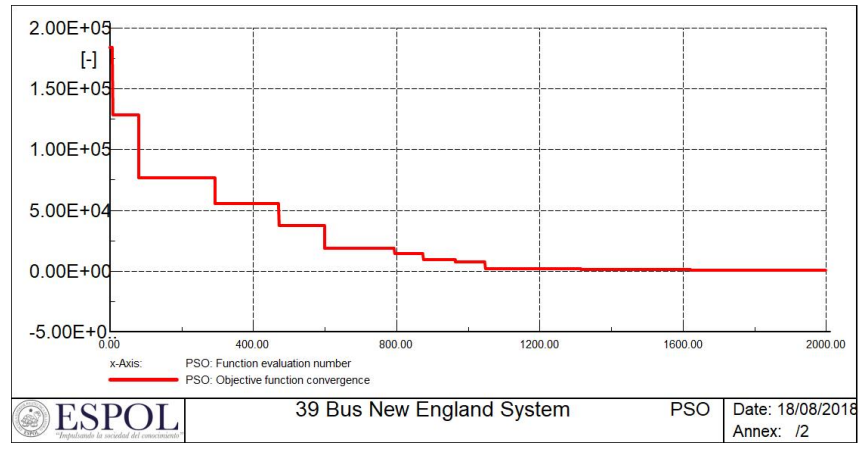

Fig. 16: Quadratic error for the identification of ten parameters, with white noise in field signal

The initial quadratic error value and the converged value in this test were very similar to the ten identified parameters case without white noise, where it started at approximately 200,000 and converged to zero.

The PSO algorithm tuned with different parameter values to the HYGOV governor for each of the four tests aimed to obtain an equal turbine mechanical power response, and turbogenerator speed responses, for each of the three and ten identified parameter cases. These can be compared in Tables 1 and 2. The results show differences between the obtained parameters tuning; nevertheless, the algorithm gave the same data for the governor responses for both cases where the field signal is with and without noise.

After we assessed the results from three different aspects, that is identification tuning, power and speed governor responses, and the objective function values, we observed the following important observation about this method: tuning after identification only gives a unique response equal to the field data for each particular test kind, which means for different events in the power system, even if these are generation or load disconnections of different capacities.

\section{DISCUSSIONS AND OBSERVATIONS}

The entry data from the test simulations in the computational software on the 39-bus power system, its load values, generation capacities, transmission lines parameters and so on, are freely available online, in IEEE information or in other works using this power system. HYGOV governor parameter information is also free online, provided by the IEEE. PowerFactory has the governor model in its database, and so this 39-bus system is very reliable.

Another optimization heuristic algorithm is the genetic algorithm, but we chose the PSO method as this algorithm is easier to understand compared to the genetic algorithm. This is supported in [17], whose authors compared both algorithms. Even though the PSO is an algorithm that does not require high computational power, the execution of each test by a conventional personal computer requires a great deal of time to complete each iteration for only one parameter identification test; indeed, it took more than 45 minutes for all cases, or more than one hour. This time can be considered very long 
with respect to other simulations in PowerFactory, like power flow, if someone needs to perform multiple simulations on computers and the algorithm is inefficient.

\section{CONCLUSIONS AND FURTHER REMARKS}

For the identification of both three and ten parameters, we obtained equal graphs for the turbine mechanical power responses and turbogenerator group speed responses, with and without noise for the field signal. It indicates that it is possible to tune a governor with variable parameter identification. Moreover, the PSO algorithm is able to adjust the governor response to the signal model desired, considering that the time constants adjustment is roughly the governor time of response.

For future research work related to governor parameter identification in primary frequency regulation in Ecuador, we recommend performing simulations based on the Ecuadorian SNI, to validate the responses in simulations with grid codes and international norms for primary control, so that the frequency response under different contingencies is closer to reality. Governor parameter tuning can also be implemented in the central generation of Ecuador. Also, the results could better contribute to research and practice if they were compared and adjusted to Ecuadorian norms on frequency control, such as the NERC briefly mentioned in the introduction of this paper.

This paper could be used as a reference for future research on speed regulator parameter identification in primary frequency control, because we performed identifications using an optimization heuristic algorithm, which was the computational tool needed to solve this work. This means that we used a program for power systems analysis. Finally, in this paper, we have proposed the basis for continuing research on primary frequency regulation in Ecuador, and, in the future, the country should be able to establish norms according to the reality of the Ecuadorian electricity system.

\section{REFERENCES}

[1] A. López, El Control Automático de Generación AGC en el SNI como un Servicio Complementario [Automatic Generation Control AGC in the SNI as a Complementary Service]. QUITO/EPN/2003, 2003. [Online]. Available: https://bibdigital.epn.edu.ec/handle/15000/5865

[2] A. Mohamed, "Analysis of grid codes and parameters identification for load frequency control," Ph.D. dissertation, ING-IND/33 SISTEMI ELETTRICI PER L'ENERGIA, 2016. [Online]. Available: https: //www.politesi.polimi.it/handle/10589/122788

[3] NERC, "Balancing and frequency control. technical document prepared by the nerc resources subcommittee," North America Electric Realiability Corporation, 116-390 Village Blvd., Princeton, NJ 08540, Tech. Rep., Jan. 2011. [Online]. Available: https://www.nerc.com/docs/ oc/rs/NERCBalancingandFrequencyControl040520111.pdf

[4] —_, "2017 frequency response annual analysis," North America Electric Realiability Corporation, 3353 Peachtree Road NE Suite 600, North Tower Atlanta, GA 30326, Tech. Rep., Nov. 2017. [Online]. Available: https://www.nerc.com/comm/OC/Documents/2017_ FRAA_Final_20171113.pdf

[5] M. Arias, "Procedimiento para el control automático de la frecuencia en el Sistema Nacional Interconectado del Ecuador [Automatic frequency control procedure in the National Interconnected System of Ecuador]," Revista Técnica CENACE, 2012. [Online]. Available: https://studylib.es/doc/686199/procedimiento-parael-control-autom\%C3\%A1tico-de-la-frecuencia
[6] J. Trujilo, Simulación del Control Potencia-Frecuencia en un Sistema Eléctrico de Potencia en MATLAB [Electric Power System Power-Frequency Control simulation in MATLAB], E. Romero, Ed. Depósito de Investigación. Universidad de Sevilla, 2016. [Online]. Available: https://idus.us.es/xmlui/bitstream/handle/11441/ 44271/TFGJAVIERTRUJILLOSOTO.pdf? sequence $=1$ \&isAllowed $=\mathrm{y}$

[7] CONELEC, "Procedimientos de Despacho y Operación [Dispatch and Operational Procedures]," Government Site, Oct. 2015. [Online]. Available: https://www.regulacionelectrica.gob.ec/wp-content/uploads/ downloads/2015/10/ProcedimientosDespacho.pdf

[8] L. Parraguez and J. Rengel, "Sobre pso (particle swarm optimization): Una implementación paralela y distribuida [About PSO (PARTICLE SWARM OPTIMIZATION): A parallel and distributed implementation]," Revista Ingeniería al Día, vol. 1, no. 2, 2015. [Online]. Available: https://www.funlam.edu.co/revistas/ index.php/lampsakos/article/view/1901

[9] M. Abido, "Optimal power flow using paricle swarm optimization," International Journal of Electrical Power \& Energy Systems, vol. 24, no. 7, pp. 563-571, Oct. 2000. [Online]. Available: https://www.sciencedirect.com/science/article/pii/S0142061501000679

[10] W. Montalvo, "Diseño y construcción de un controlador pid autosintonizable mediante inteligencia de enjambres para determinar el comportamiento colectivo de los sistemas pertenecientes a procesos estudiados en el cerfin-secap [Design and Construction of a SelfTuneable PID Controller Using Swarm Intelligence to Determine the Collective Behavior of the Systems Belonging to Processes Studied at CERFIN-SECAP]," Master's thesis, Maestría en Automatización y Control Electrónico Industrial, Sep. 2015. [Online]. Available: https://bibdigital.epn.edu.ec/handle/15000/11799

[11] R. Lliuyacc, "Sintonización de un controlador pid usando particle swarm optimization para el agc de un sistema eléctrico multiárea [PID Controller Tuning Using Particle Swarm Optimization for a Multi-Area Power System AGC]," Master's thesis, Máster en Sistemas de Energía Eléctrica, Aug. 2014. [Online]. Available: https://idus.us.es/xmlui/handle/11441/27037

[12] V. Koritarov and L. Guzowski, "Review of existing hydroelectric turbine-governor simulation models," Decision and Information Sciences, Argonne National Laboratory, Tech. Rep., 2013. [Online]. Available: https://ceeesa.es.anl.gov/projects/psh/ANL_DIS13_05_Review_of_Existing_Hydro_and_PSH_Models.pdf

[13] PowerWorld, "Governor hygov," PowerWorld, Tech. Rep., 2018. [Online]. Available: https://www.powerworld.com/WebHelp/ Content/TransientModels_HTML/GovernorHYGOVandHYGOVD. $\mathrm{htm}$ ?TocPath=TransientStabilityAdd-On\%20(TS)\%7CTransient\% 20Models\%7CGenerator\%7CGovernor\%7C38

[14] J. Marquéz, "Ruido de datos, señales e imágenes [Noise from data, signals and images]," Universidad Nacional Autónoma de Méjico, 2014. [Online]. Available: http://www.academicos.ccadet.unam. $\mathrm{mx} /$ jorge.marquez/cursos/imagenes_neurobiomed/Ruido.pdf

[15] IEEE, "IEEE 10 generator 39 bus system," IEEE, Tech. Rep., 2013. [Online]. Available: https://www.researchgate.net/file. PostFileLoader.html?id=55019916f079ed 153f8b4598\&assetKey $=$ AS $\%$ 3A273740330405917\%401442276188879

[16] G. Stefopoulos, P. Georgilakis, N. Hatziargyriou, and S. Meliopoulos, A Genetic Algorithm Solution to the Governor-Turbine Dynamic Model Identification in Multi-Machine Power Systems, IEEE, Ed. IEEE, 2008. [Online]. Available: https://ieeexplore.ieee.org/abstract/document/ 1582336

[17] J. A. Jiménez, R. Arango, and L. Jiménez, "Métodos de busqueda usando los algoritmos de enjambre de partículas y genético [Search methods using particle swarm and genetic algorithms]," Universidad Católica Luis Amigo, 2016. [Online]. Available: https: //www.funlam.edu.co/revistas/index.php/lampsakos/article/view/1901 